\title{
Measurement of instantaneous left ventricular dimension and filling rate in man, using echocardiography
}

\author{
D. G. Gibson and D. Brown \\ From the Cardiac Department, Brompton Hospital, London, and the Medical Computer Centre, Westminster \\ Hospital, London
}

A technique has been devised for deriving instantaneous measures of left ventricular dimension and its rate of change from a standard echocardiogram of the left ventricular cavity. Using the cube of the dimension as a measure of left ventricular volume, estimates of filling rates were also made. The characteristics of left ventricular filling were studied in 10 normal subjects, and in 50 patients with different types of heart disease. In normal subjects, the peak rate of increase of left ventricular dimension had a mean value of $I I \mathrm{~cm} / \mathrm{sec}$, corresponding to a filling rate of $880 \mathrm{ml} / \mathrm{sec}$. In the presence of mitral regurgitation due to ruptured chordae tendineae, the peak rate of increase of left ventricular dimension and volume was greatly increased to $22 \mathrm{~cm} / \mathrm{sec}$ and $2400 \mathrm{ml} / \mathrm{sec}$, respectively, while rheumatic mitral stenosis caused a conspicuous reduction in both (mean $6.9 \mathrm{~cm} / \mathrm{sec}$ and $210 \mathrm{ml} / \mathrm{sec}$ ). Aortic regurgitation was associated with an increased peak left filling rate of $1600 \mathrm{ml} / \mathrm{sec}$, though the rate of change of left ventricular dimension was within normal limits, while left ventricular disease did not appear to be associated with any consistent abnormality. In all groups of patients, except those with rheumatic mitral stenosis, the filling pattern consisted of an initial period of accelerating outward wall movement lasting 0.1 to $0.13 \mathrm{sec}$, followed by progressive reduction in velocity until the onset of atrial systole. This pattern appeared to reflect a discontinuity in the factors governing ventricular filling whose cause was not apparent from the present study.

Although the course of ventricular filling was described in anaesthetized animals as long ago as 1906 by Henderson, Scarbrough, and Chillingworth, there is still little information on this subject in man, either in normal subjects or in patients with heart disease. Such studies have become possible with the development of the echocardiographic method of measuring left ventricular dimensions (Chapelle and Mensch, 1969; Popp et al., 1969), which gives excellent resolution in time, allowing rapid movements to be analysed. However, in order to do this, a continuous record of the distance between echoes arising from the interventricular septum and the posterior wall of the left ventricle is required, which is very laborious to derive manually. We have therefore used a simple computer technique to register the position of these two echoes throughout the cardiac cycle, and to derive from them instantaneous left ventricular dimension and volume, with their respective rates of change. Received 4 June 1973.
Its use has made it possible to study ventricular filling in normal subjects and in patients with a variety of different types of heart disease.

\section{Methods}

Echocardiographic methods

Echocardiographic measurements were made with an Ekoline ' 20 ' ultrasonoscope, using a $2.25 \mathrm{mHz} \mathrm{I} \cdot 25 \mathrm{~cm}$ diameter probe with a repetition frequency of $1000 / \mathrm{sec}$, and in all cases a simultaneous electrocardiogram was recorded. With the transducer in the fourth left interspace, the characteristic echo from the anterior cusp of the mitral valve was first identified. The transducer was then angled to locate first the mitral valve ring and then to make a record demonstrating interventricular septum and posterior wall. Measurements were made only on records showing clear continuous endocardial echoes from both structures throughout the cardiac cycle. These echoes usually appear as discrete lines separated from adjoining structures by non-reflecting myocardium. Those from the posterior wall are behind those originating from the mitral valve apparatus and frequently 
reflect less ultrasonic energy than pericardium or posterior mediastinal structures. The identity of the interventricular septum was confirmed by its double structure and its position anterior to the mitral valve ring. The internal dimension of the left ventricle was taken as the distance from the posterior of the two septal echoes to the endocardial surface of the posterior wall measured, using the scale of centimetres superimposed on all records.

\section{Analysis of echocardiograms}

The method used is being described in detail elsewhere (D. Brown and D. G. Gibson, unpublished). In brief, the echocardiogram to be studied was positioned on a digitizing table (DMAC) and a crosswire cursor moved along each of the two echoes representing the septum and posterior wall, a series of approximately 100 points being defined on each by pressing an interrupt button. Since the cursor emitted low frequency radio waves, its position could be sensed by detection coils in the gantry below the table, and converted into electrical signals representing its $\mathrm{x}$ and $\mathrm{y}$ co-ordinates with a resolution of $0.01 \mathrm{~cm}$ each time the interrupt button was pressed. This information, together with calibration signals corresponding to $I \mathrm{~cm}$, half a second, and the $R R$ interval of the beat being studied, and a correction for lack of rectilinearity in position of the echocardiogram on the digitizing table was stored by the IBM I800 computer at Westminster Hospital, working under a multiprogramming operating system. A pair of linearly interpolated sets of 129 data points was derived, corresponding to each of the two echoes, and then the coordinates of the points representing the left ventricular wall echo were subtracted from those of the interventricular septum to give the instantaneous left ventricular dimension, which, after smoothing with a 3 point 'triangular' filter, was displayed together with its first differential by an xy plotter. Similar curves were also produced for the cube of the dimension, corresponding to left ventricular volume expressed in $\mathrm{ml}$, also with its first differential. Typical output curves are shown in Fig. I-3; in all zero time corresponds to the start of the inscription of the $Q$ wave of the electrocardiogram.

\section{Patients}

Sixty patients were studied. They were divided into 6 groups.

Group I consisted of Io patients considered to have normal cardiac function who were convalescing from ENT or orthopaedic procedures. Their ages ranged from $13-50$.

Group 2 consisted of 10 patients who were awaiting mitral valvotomy. All had clear-cut evidence of mitral stenosis with no more than minimal regurgitation and no evidence of other valvular lesions. Eight were in atrial fibrillation and 2 were in sinus rhythm.

Group 3 consisted of ro patients with pure mitral regurgitation, subsequently proved at operation to be due to ruptured chordae tendineae. All had mitral valve diastolic closure rates greater than $100 \mathrm{~mm} / \mathrm{sec}$ demon- strated by echocardiography; 7 were in sinus rhythm and 3 in atrial fibrillation.

Group 4 consisted of 12 patients with rheumatic mitral valve disease, both stenotic and regurgitant, who were awaiting mitral valve replacement. Eleven were in atrial fibrillation; none had significant aortic valve disease.

Group 5 consisted of 8 patients with severe aortic regurgitation, awaiting aortic valve replacement. None had mitral valve disease and only one was in atrial fibrillation, the remainder being in sinus rhythm.

Group 6 consisted of ro patients with compensated left ventricular disease. Of these, 3 had ischaemic heart disease, $\mathbf{2}$ had aortic stenosis, 2 had normally functioning aortic Starr-Edwards prostheses, 2 had cardiomyopathy associated with a large left ventricular cavity, and I had hypertrophic cardiomyopathy. Two were in atrial fibrillation and the remainder were in sinus rhythm. None had evidence of aortic regurgitation or of mitral valve disease.

Heart rate was determined from the RR interval of the cardiac cycle being studied. Left ventricular enddiastolic and stroke volumes were derived from the computer output, ejection fraction being calculated as stroke volume divided by end-diastolic volume. The first differentials of the dimension and volume curves were used to obtain their respective peak rates of change and also to time events during diastole. The onset of ventricular filling was taken as the time when the sign of the first differential moved from negative to positive at the end of ventricular ejection. Since there was no clear division between the rapid filling phase and diastasis, the time when the filling rate had declined to 20 per cent of its peak value was arbitrarily chosen as giving some indication when this occurred. The end of ventricular filling was taken as the time when the first differential finally became negative at the end of diastole (Fig. I-3). The increase in left ventricular volume in the time interval between the start of ventricular filling and peak filling rate was measured and expressed as a percentage of the total stroke volume for the beat in question. The peak rate of change of dimension ( $\mathrm{dL} / \mathrm{dt}$ ) was divided by the instantaneous dimension at which it occurred, read directly from the print-out, to give the ratio $\mathrm{dL} / \mathrm{dt} / \mathrm{L}$, a normalized lengthening rate with the dimensions $\mathrm{sec}^{-1}$.

In patients with rheumatic mitral valve disease, no clear early diastolic flow maximum was apparent, but, instead, relatively low flows were maintained throughout diastole (Fig. 2). No attempt was made to measure the timing of peak filling rate or related variables in these patients, and since the majority were in atrial fibrillation, the effect of atrial systole in this group could not be assessed.

Statistical analysis was by Student's ' $t$ ' test for the significance of differences between means, and by the method of least squares for linear regression (Dixon and Massey, 1969).

\section{Critique of methods}

I) Measurement of distance The depth calibration of the ultrasonoscope was checked in water by direct 

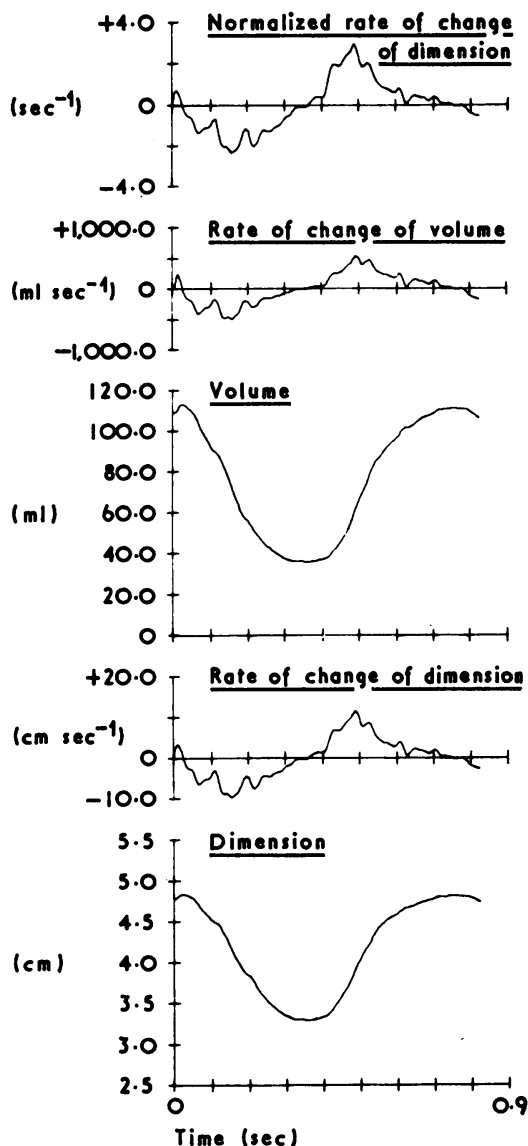

FIG. I Computer output of left ventricular dimension and its rate of change throughout a single cardiac cycle. Values for left ventricular volume are derived as the cube of the instantaneous dimension. In this and subsequent records, zero time corresponds to the inscription of the $Q$ wave of the electrocardiogram.

measurement of the distance from the transducer to the front surface of the piece of perspex perpendicular to the ultrasound beam. Over the range 5-10 cm, there was agreement between the two methods to within 2 per cent.

2) Frequency response of echocardiograph This was measured in vitro by observing the response to a step change in the target surface, and the results will be reported in detail elsewhere (W. A. Seed and D. G. Gibson, unpublished). Using this method, the frequency response of the instrument was found to be flat to at least $500 \mathrm{~Hz}$.

3) Frequency response of digitizing system The frequency response of the digitizing and interpolating procedure was investigated, using, as input, a single impulse traced with the cursor used for processing
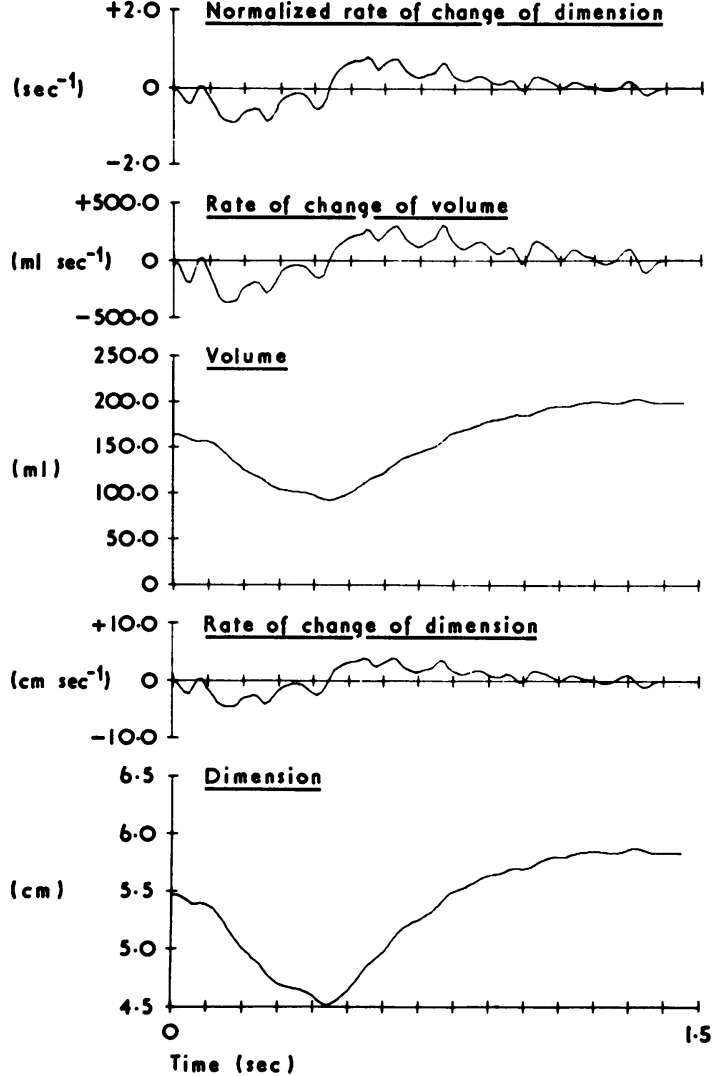

FIG. 2 Computer output of changes in left ventricular dimension and volume in a patient with mitral stenosis. The rate of increase of dimension and volume during diastole are strikingly reduced.

echocardiograms. Fourier analysis was performed on the output after smoothing, which showed a 5 per cent reduction in amplitude below that predicted at $10 \mathrm{~Hz}$. Fourier analysis of to representative records of LV dimensions showed that there was no significant information contained at frequencies greater than $5 \mathrm{~Hz}$, an example being given in Fig. 4. The frequency response of the echocardiograph and digitizing system was thus entirely adequate to record the wall movements described without distortion.

4) Reproducibility This was assessed as the root mean square difference between pairs of determinations of left ventricular dimension at end-systole and enddiastole, and of maximum rate of increase in left ventricular dimension during filling. These were performed for 25 pairs of measurements made by the same observer on the same record, and also in 15 patients, all in sinus rhythm, between pairs of records made at different times on the same patient. For duplicate determinations 


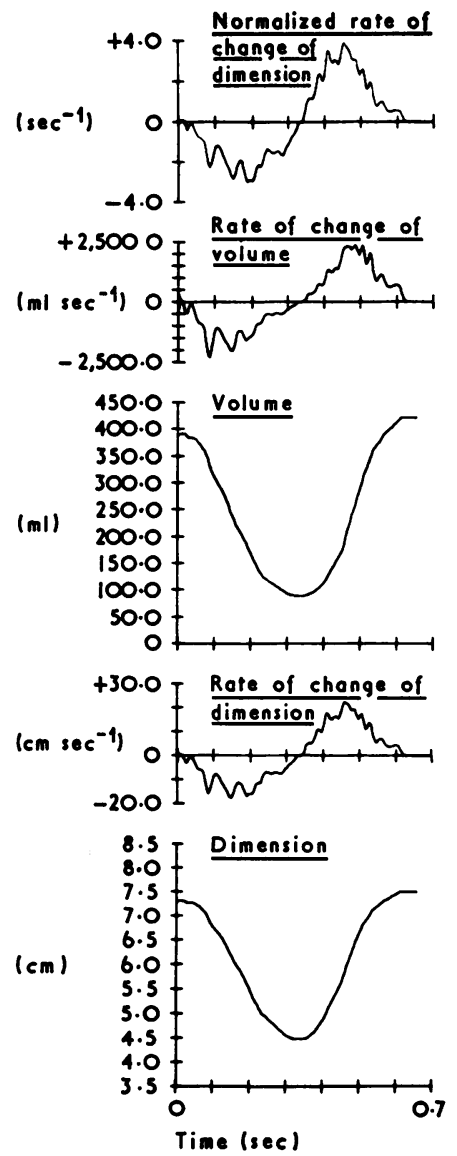

FIG. 3 Computer output of changes in left ventricular dimension and volume in a patient with mitral regurgitation due to ruptured chordae tendineae.

on the same record, the root mean square difference was I. $6 \mathrm{~mm}$ for end-diastolic dimension, I.7 $\mathrm{mm}$ for endsystolic dimension, and $1.5 \mathrm{~cm} / \mathrm{sec}$ for peak rate of increase of left ventricular dimension. The root mean square differences for observations made at different times on the same patient were somewhat larger, being $2.0 \mathrm{~mm}$ for end-diastolic dimension, $1.9 \mathrm{~mm}$ for endsystolic dimension, and $1.8 \mathrm{~cm} / \mathrm{sec}$ for peak rate of increase of left ventricular dimension. Comparison of the same record, processed with and without the 3 point smoothing filter, showed no significant difference between any of these three variables.

5) Relation between ventricular geometry and echocardiographic dimension Echocardiographic dimension is related to the mean minor axis of the left ventricular ellipsoid (Gibson, I973). This reflects the condition that a significant proportion of incident ultrasound energy returns to the transducer only from inter-
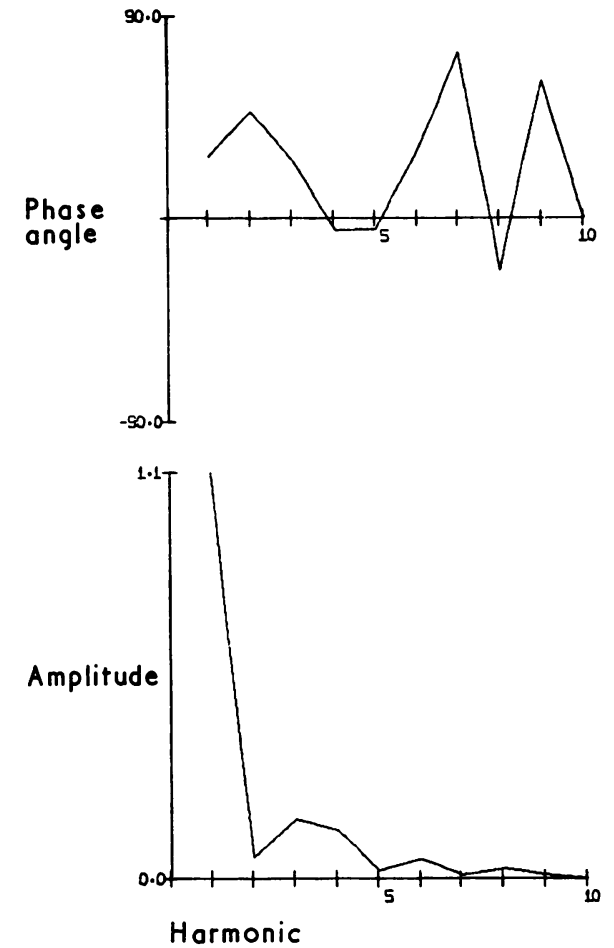

FIG. 4 Fourier analysis of left ventricular wall movement in a patient with mitral regurgitation. The amplitude and phase angle of the first ten harmonics are shown, the fundamental being the $R R$ interval of the beat being studied.

faces perpendicular to the beam so that satisfactory echoes from anterior and posterior surfaces of an ellipsoid can only be obtained when the beam passes along either the major axis or one of the minor axes. Differences between echocardiographic dimension and mean minor axis probably represent departures from this idealized geometry, due to an additional effect of left ventricular shape. The mean minor axes in the anteroposterior and lateral planes are similar in magnitude at end-systole and end-diastole, indicating that the cross-section of the region of the left ventricular cavity from which the echocardiographic dimension originates, remains approximately circular throughout the cycle.

6) Derivation of left ventricular volume Estimation of left ventricular volume from a single dimension assumes that left ventricular cavity shape is uniform from patient to patient. This is confirmed by angiographic studies showing a relation between the major and minor axes of the left ventricular ellipsoid over a wide range of ventricular volume (Dodge and Baxley, 1969). Use of the cube of the left ventricular dimension as a measure of volume has a simple theoretical basis, as the volume of an ellipsoid is given by $4 / 3 \pi a^{2} b$, where $a$ is the 
semiminor axis and $b$ the semimajor axis. Since the echocardiographic dimension is approximately $2 a$, the simple cube relation applies when the semimajor axis is $(2 \pi / 3) a$ or approximately twice the semiminor axis. In practice, the ratio of major to minor axis varies from approximately $3: 1$ when cavity size is small, to $I \cdot 4: I$ when it is very large (Frimer et al., 1970; Teichholz et al., 1972). Estimation of volumes derived from the simple cube relation are therefore subject to error, when the left ventricle is greatly dilated, or in the presence of dyskinesia or abnormalities of cavity shape. Nevertheless, the results of previous studies, in which enddiastolic or end-systolic volumes have been compared with those derived from angiography (Feigenbaum et al., 1969; Pombo, Troy, and Russell, 197I) or echocardiographic measures of stroke volume compared with those measured directly (Popp and Harrison, 1970), suggest that, under many conditions, these errors are not large.

\section{Results}

\section{Normal subjects}

In the normal group, the mean heart rate was 78 beats/min, left ventricular end-diastolic dimension $5.1 \mathrm{~cm}$, and end-systolic dimension $3.7 \mathrm{~cm}$. The corresponding values of end-diastolic volume and stroke volume were $130 \mathrm{ml}$ and $81 \mathrm{ml}$, respectively. Peak rate of increase of left ventricular dimension was I I cm/sec or $2.5 \mathrm{sec}^{-1}$ when divided by instantaneous dimension, and this was achieved 0. I sec after the start of filling. The peak filling rate was $880 \mathrm{ml} / \mathrm{sec}$, and during the initial period of diastole, 45 per cent of the stroke volume entered the left ventricle. Filling rate had declined to 20 per cent of its peak value after 0.21 sec and the total filling period was $0.44 \mathrm{sec}$. The mean increase in left ventricular volume during atrial systole was $8 \mathrm{ml}$, though it was undetectable in 5 . These results are given in detail in Tables $I$ and 2.

\section{Mitral stenosis}

The most striking abnormality in this group was a reduction in the peak rate of increase of left ventricular dimension to $6.9 \mathrm{~cm} / \mathrm{sec}(P<0.01$ with respect to normal) and of peak filling rate to $210 \mathrm{ml} / \mathrm{sec}$ $(\mathbf{P}<0.001$ with respect to normal). The pattern of left ventricular filling was also significantly altered, since this low flow rate was maintained throughout diastole and had only declined to 20 per cent of its peak rate after $0.42 \mathrm{sec}(\mathrm{P}<0.0 \mathrm{I}$ with respect to normal).

\section{Mitral regurgitation}

The resting heart rate was significantly higher in this group at IOI beats/min. End-diastolic dimension, however, was significantly raised at $6.9 \mathrm{~cm}$, ( $P<0.01$ with respect to normal). The presence of severe regurgitation was reflected in the large stroke volume of $220 \mathrm{ml}(\mathrm{P}<0.00 \mathrm{I}$ with respect to normal), from an end-diastolic volume of $360 \mathrm{ml}(P<0.001$ with respect to normal). The rate of increase of left ventricular dimension was conspicuously increased at $22 \mathrm{~cm} / \mathrm{sec}$ and also the peak filling rate to $2400 \mathrm{ml} /$ $\sec (P<0.01$ and 0.001 , respectively, with respect to normal). Peak filling rate was achieved within $0.10 \mathrm{sec}$ of the start of filling, when 50 per cent of

TABLE I Mean values $\pm I$ standard deviation

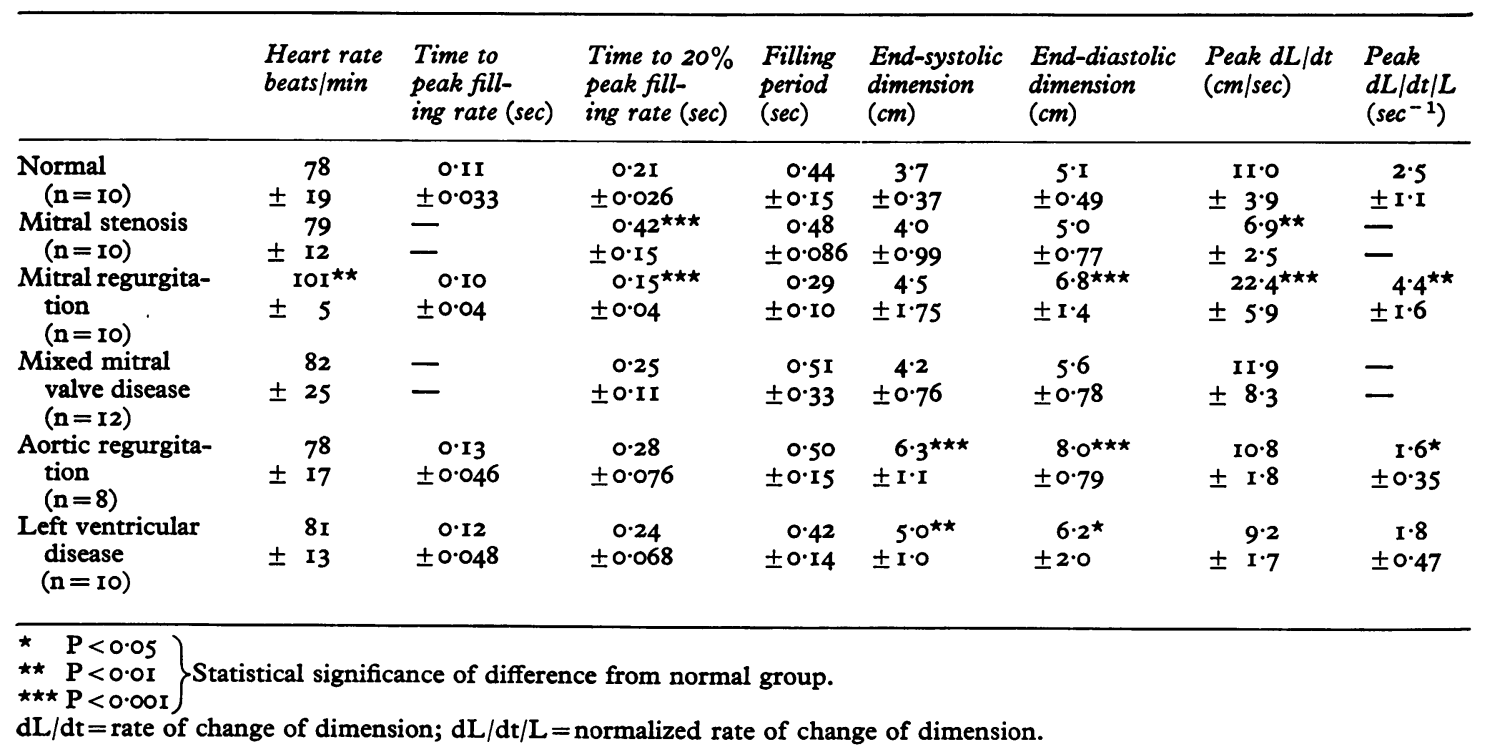


TABIE 2 Mean values $\pm I$ standard deviation

\begin{tabular}{|c|c|c|c|c|c|c|}
\hline & $\begin{array}{l}\text { End-diastolic } \\
\text { volume }(\mathrm{ml})\end{array}$ & $\begin{array}{l}\text { LV stroke } \\
\text { volume }(\mathrm{ml})\end{array}$ & $\begin{array}{l}\text { Ejection } \\
\text { fraction }(\%)\end{array}$ & $\begin{array}{l}\text { Peak filling } \\
\text { rate }(\mathrm{ml} / \mathrm{sec})\end{array}$ & $\begin{array}{l}\text { LV volume } \\
\text { increase } \\
\text { during atrial } \\
\text { systole }(\mathrm{ml})\end{array}$ & $\begin{array}{l}\% \text { total } \\
\text { SV entered } \\
\text { LV by peak } \\
\text { flow }(\%)\end{array}$ \\
\hline $\begin{array}{l}\text { Normal } \\
(n=10) \\
\text { Mitral stenosis } \\
(n=10) \\
\text { Mitral regurgitation } \\
(n=10) \\
\text { Mixed mitral valve disease } \\
(n=12) \\
\text { Aortic regurgitation } \\
(n=8) \\
\text { Left ventricular disease } \\
(n=10)\end{array}$ & $\begin{array}{l}130 \\
\pm 36 \\
120 \\
\pm 43 \\
360^{\star \star \star} \\
\pm 200 \\
180 \\
\pm 65 \\
560^{\star \star \star} \\
\pm 170 \\
240^{\star \star} \\
\pm 130\end{array}$ & $\begin{array}{r}81 \\
\pm \quad 25 \\
56 \\
\pm 19 \\
220 \\
\pm 95 \\
96 \\
\pm 54 \\
260^{\star \star \star} \\
\pm 51 \\
\pm 77 \\
\pm 33\end{array}$ & $\begin{array}{l}61 \\
\pm \quad 7 \\
48^{\star \star} \\
\pm 11 \\
68 \\
\pm 19 \\
53 \\
\pm 16 \\
56 \\
\pm 9 \\
39^{\star \star \star} \\
\pm 15\end{array}$ & $\begin{aligned} & 880 \\
\pm & 295 \\
& 210^{\star \star \star} \\
\pm & 63 \\
& 2400^{\star \star \star} \\
\pm & 1100 \\
& 720 \\
\pm & 390 \\
& 1600^{\star \star} \\
\pm & 570 \\
& 750 \\
\pm & 210\end{aligned}$ & $\begin{array}{l}\quad 9 \\
\pm 9.5 \\
- \\
3^{8 \star \star} \\
\pm 31 \\
= \\
\pm 9 \\
\pm 8 \\
\pm 11\end{array}$ & $\begin{array}{l}\quad 45 \\
\pm 9 \\
- \\
\pm 10 \\
- \\
-19^{\star \star} \\
\pm 6 \\
36 \\
\pm 17\end{array}$ \\
\hline
\end{tabular}

$\star \quad P<0.05$

$\star \star \quad P<0.01\}$ Statistical significance of difference from normal group.

$\star \star \star P<0.001$

the stroke volume had entered the left ventricle, and declined to 20 per cent of its peak value within $0.15 \mathrm{sec}$, significantly more rapidly than normal $(P<0.01)$. The mean increase in left ventricular volume during atrial systole was $38 \mathrm{ml}$, significantly greater than in the normal group $(P<0.01)$.

\section{Rheumatic mixed mitral valve disease}

Mean values of heart rate, stroke volume, peak filling rates, and left ventricular filling times, taken singly, were not significantly different from normal. End-diastolic volume, however, was increased to a mean value of $180 \mathrm{ml}(P<0.05)$.

\section{Aortic regurgitation}

The presence of severe aortic regurgitation was reflected in the high end-diastolic volume of $560 \mathrm{ml}$ and stroke volume of $260 \mathrm{ml}$ (both $P<0.001$ with respect to normal). The peak rate of increase of left ventricular dimension did not differ significantly from normal, but when divided by simultaneous left ventricular dimension, it was significantly less at $\mathrm{I} .6 \mathrm{sec}^{-1}(\mathrm{P}<0.05)$, because of the large cavity size. The peak filling rate, however, was increased at $1600 \mathrm{ml} / \mathrm{sec}$, which was greater than normal $(\mathbf{P}<0.01)$, but less than in patients with mitral regurgitation $(P<0.05)$, and reflected entry of blood into the left ventricle from the aortic root as well as through the mitral valve. Peak filling rate was reached after $0.13 \mathrm{sec}$, when only 19 per cent of the total stroke volume had entered the left ventricle, considerably less than normal $(P<0.01)$. Filling rate had declined to 20 per cent of its peak value in $0.28 \mathrm{sec}$, a value not significantly different from normal, but longer than in the group with mitral regurgitation $(\mathrm{P}<0.00 \mathrm{I})$. The volume increase during atrial systole was small, being undetectable in 3 patients, and having a mean value of $14 \mathrm{ml}$, not significantly different from normal, but less than in the patients with mitral regurgitation $(P<0.01)$.

\section{Left ventricular disease}

Although end-diastolic volume was increased in this group of patients with compensated left ventricular disease, to a mean value of $240 \mathrm{ml}(P<0.01$ with respect to normal) and ejection fraction reduced to 39 per cent $(P<0.01)$, values of heart rate, stroke volume, peak rate of increase of left ventricular dimension filling rate, filling times, and volume increase during atrial systole were all within normal limits.

\section{Relation between stroke volume and filling rate}

In patients with no rheumatic mitral disease or aortic regurgitation, there was a highly significant relation between stroke volume and peak filling rate.

Stroke volume $=0.081$ (filling rate) $+18, r=$ $0.93, P<0.001$ with a standard error of the estimate of $33 \mathrm{ml}$.

In patients with rheumatic mitral valve disease, with or without mitral regurgitation, peak filling rate was less than would be predicted from the value of stroke volume using the previous regression equation, but was given by

Stroke volume $=0.17$ (filling rate) $+I 2, r=0.79$, $P<0.001$, the standard error of the estimate being $37 \mathrm{ml}$.

In patients with aortic regurgitation, peak filling rate was also less than would be predicted 
from stroke volume, though there was no significant relation between the two within the group.

\section{Discussion}

The characteristics of left ventricular filling may be described either in terms of changes in left ventricular dimension, or of left ventricular volume, derived as the cube of the dimension. Dimensional changes, derived directly from the echocardiogram, depend not only on the volume entering the cavity during diastole, but also on its dimensions, a given inflow being accommodated with a smaller proportional change in dimension if the end-systolic volume is large. Since the echocardiographic dimension is closely related to the mean minor axis of the left ventricular ellipsoid, deductions can be made about a hoop of myocardium at a position where the cross-section of the cavity is approximately circular in a plane perpendicular to the long axis. Left ventricular volume has been shown to approximate to the cube of the echocardiographic dimension, so that diastolic filling may also be expressed in terms of volume changes, the rate of increase representing mitral valve flow, in the absence of aortic regurgitation or a ventricular septal defect. Such estimates are subject to the limitation that assumptions are made about ventricular shape, but, as has been previously pointed out, under many conditions these appear to be justified in practice.

Ventricular volume changes in the mammalian heart were first described in detail by Henderson et al. (1906), who noted an early diastolic period of rapid filling followed by a period of diastasis or reduced inflow. Later authors stressed the additional importance of atrial systole (Patterson, Piper, and Starling, 1914; Wiggers and Katz, 192I), and these results have frequently been confirmed by a variety of methods in awake and anaesthetized animals (Rushmer, 1954; Hawthorne, 196I ; Noble et al., 1969; Horwitz and Bishop, 1972). Published records of ventricular segment lengths (Braunwald et al., 196r) and angiographic observations (Dodge and Baxley, 1969) suggest that similar changes occur in man.

The present results indicate that, in normal subjects, the initial phase of left ventricular filling was one of accelerating wall movement, lasting 0. I I sec, when the rate of change of left ventricular dimension rose progressively to reach a peak value of II $\mathrm{cm} / \mathrm{sec}$. The corresponding value for peak rate of increase of left ventricular volume was $880 \mathrm{ml} / \mathrm{sec}$, reflecting peak flow across the mitral valve. This has been measured directly in the dog by electromagnetic flowmeter by Williams et al. (1970), who recorded peak values of $130-180 \mathrm{ml} / \mathrm{sec}$ at a stroke volume of
Io ml, while Nolan et al. (1969) noted values of $170 \mathrm{ml} / \mathrm{sec}$ across mitral Starr-Edwards prostheses in the calf. In view of the relation between stroke volume and peak left ventricular filling rate, these results are directly comparable to those in the present study.

The phase of acceleration ended abruptly and was followed by progressive reduction in the rate of outward wall movement, which had declined to 20 per cent of its peak value $0.21 \mathrm{sec}$ after the onset of ventricular filling. The mechanism underlying this sudden change in the velocity of wall movement was not apparent, but it must reflect a striking discontinuity in the conditions determining left ventricular filling. This characteristic pattern occurred in all groups of patients except those with mitral stenosis, where the factor limiting the flow of blood into the ventricle throughout diastole was presumably the narrowed valve orifice itself.

In patients with left ventricular disease, ventricular dimensions and end-diastolic volume were all significantly greater than normal, while ejection fraction was reduced. Nevertheless, the peak rate of increase of left ventricular dimension, and the corresponding value for rate of change of left ventricular volume were not different from those in the normal group. There was thus no evidence that, in this group of patients, left ventricular disease per se caused any change in the pattern of left ventricular filling, except that a low stroke volume was associated with corresponding reduction in peak filling rate. Since the same relation between the two variables also applied in normal subjects, and in patients with pure mitral regurgitation, a reduction in peak filling rate did not constitute evidence of 'inflow obstruction'.

In patients with pure mitral regurgitation, the end-diastolic dimension was large and its peak rate of increase during diastole was approximately double the value in the normal group. Though enddiastolic volume, stroke volume, and peak filling rate were all abnormally large, the pattern of left ventricular filling was normal with respect to the duration of the phase of acceleration, the percentage of the total stroke volume entering the left ventricle during it, and the relation between stroke volume and peak filling rate. This high filling rate could not be attributed directly to a large left ventricular cavity size since, in aortic regurgitation, peak filling rate was lower though both stroke volume and cavity size were greater.

The present study also clearly demonstrated the altered pattern of left ventricular filling occurring in rheumatic mitral valve disease. In the presence of pure mitral stenosis, the peak rate of increase in left ventricular dimension was reduced to a little over 
half its normal value and this low rate was maintained throughout diastole. This was reflected in a very low mitral valve flow with loss of the normal division into a rapid early diastolic phase followed by diastasis. The significance of the disturbance to mitral valve function becomes apparent when it is recollected that these low filling rates were achieved only with considerable diastolic pressure differences across the valve, while flow rates up to twenty times as great occurred in the absence of measurable gradient in patients with ruptured chordae. In the presence of mixed mitral valve disease, ventricular filling rates were within the normal range, whether expressed in terms of rates of change of dimension or of volume. In many cases, however, these were associated with a large stroke volume due to the presence of mitral regurgitation. When the relation between stroke volume and peak filling rate was compared to that in patients with no mitral stenosis, it was apparent that in patients with rheumatic mitral valve disease, with or without regurgitation, peak filling rate was lower than would be anticipated from the stroke volume, implying the presence of functional mitral stenosis throughout the group.

The ventricular filling pattern in aortic regurgitation was also characteristic. Though peak filling rate was increased, the rate of increase of dimension was normal and the rate of increase of unit length of muscle reduced, since the left ventricular cavity was greatly enlarged. The duration of the initial phase of left ventricular filling was longer than in mitral regurgitation, while peak filling rate was less, and only 19 per cent of the stroke volume entered the left ventricle during the phase of acceleration. These differences probably reflect the characteristics of ventricular filling occurring predominantly from the aortic root rather than through the mitral valve. The abnormal route of entry may also have accounted for the smaller change in ventricular volume during atrial systole compared with patients with mitral regurgitation. This could not be ascribed to better left ventricular function in patients with aortic regurgitation, since their ejection fraction was significantly lower than those with mitral regurgitation, while premature mitral valve closure was excluded as a cause by a normal mitral echogram in all patients.

In addition to giving an overall picture of ventricular filling in man, the present methods may also be of practical value in assessing patients for cardiac surgery. Echocardiography has been of considerable value in diagnosing the presence of rheumatic mitral valve disease, and in giving some indication of the physical characteristics of the anterior cusp. There is, however, little correlation between dias- tolic closure rate and the presence of stenosis or regurgitation. Measurement of left ventricular dimensions, volumes, and their rates of change allow the physiological consequences of mitral valve disease to be assessed with minimal disturbance to the patient, and when combined with pressure measurements, are capable of giving a very comprehensive picture of mitral valve function.

\section{References}

Braunwald, E., Frye, R. L., Aygen, M. M., and Gilbert, J. W., Jr. (196I). Studies on Starling's law of the heart III: Observations in patients with mitral stenosis and atrial fibrillation on the relationships between left ventricular end-diastolic segment length, filling pressure and the characteristics of ventricular contraction. Fournal of Clinical Investigation, 39, 1874.

Chapelle, M., and Mensch, B. (1969). Étude des variations du diamètre ventriculaire gauche chez l'homme par échocardiographie transthoracique. Archives des Maladies $d u$ Coeur et des Vaisseaux, 62, 1505.

Dixon, W. J., and Massey, F. J. Jr. (1969). Introduction to Statistical Analysis. McGraw-Hill, New York.

Dodge, H. T., and Baxley, W. A. (1969). Left ventricular volume and mass and their significance in heart disease. American fournal of Cardiology, 23, 528.

Feigenbaum, H., Wolfe, S. B., Popp, R. L., Haine, C. L., and Dodge, H. T. (1969). Correlation of ultrasound with angiocardiography in measuring left ventricular diastolic volume (abstract). American fournal of Cardiology, 23, I I I.

Frimer, M., Porter, C. M., Rackley, C. E., and Dodge, H. T. (1970). Left ventricular chamber geometry and function in heart disease (abstract). Circulation, 40, Suppl., I I I, p. 85.

Gibson, D. G. (1973). Estimation of left ventricular size by echocardiography. British Heart fournal, 35, 128.

Hawthorne, E. W. (196r). Instantaneous dimensional changes of the left ventricle in dogs. Circulation Research, 9, 1 10.

Henderson, Y., Scarbrough, M. McR., and Chillingworth, F. P. (1906). The volume curve of the ventricle of the mammalian heart, and the significance of this curve in respect to the mechanics of the heart-beat and the filling of the ventricles. American fournal of Physiology, 16, 325.

Horwitz, L. D., and Bishop, V. S. (1972). Left ventricular pressure-dimension relationships in the conscious dog. Cardiovascular Research, 6, 163.

Noble, M. I. M., Milne, E. N. C., Georke, R. J., Carlsson, E., Domenech, R. J., Saunders, K. B., and Hoffman, J. I. E. (1969). Left ventricular filling and diastolic pressurevolume relations in the conscious dog. Circulation Research, $24,269$.

Nolan, S. P., Stewart, S., Fogarty, T. J., Dixon, S. H., and Morrow, A. G. (1969). In vivo studies of instantaneous blood flow across mitral ball-valve prostheses: effects of cardiac output and heart rate on transvalvular energy loss. Annals of Surgery, 169, 551 .

Patterson, S. W., Piper, H., and Starling, E. H. (1914). The regulation of the heart beat. Fournal of Physiology, 48, 465 .

Pombo, J. F., Troy, B. L., and Russell, J. O., Jr. (197I). Left ventricular volumes and ejection fraction by echocardiography. Circulation, 43, 480 .

Popp, R. L., and Harrison, D. C. (1970). Ultrasonic cardiac echography for determining stroke volume and valvular regurgitation. Circulation, 41, 493.

Popp, R. L., Wolfe, S. B., Hirata, T., and Feigenbaum, $H$. (1969). Estimation of right and left ventricular size by ultrasound. A study of the echoes from the interventricular septum. American fournal of Cardiology, 24, 523. 
Rushmer, R. F. (1954). Continuous measurements of left ventricular dimensions in intact, unanesthetized dogs. Circulation Research, 2, 14.

Teichholz, L. E., Kreulen, T. H., Herman, M. V., and Gorlin, R. (1972). Problems in echocardiographic volume determinations: echo-angiographic correlations (abstract). Circulation, 46, Suppl. II, p. 75.

Wiggers, C. J., and Katz, L. N. (I92I). The contour of the ventricular volume curve under different conditions. American fournal of Physiology, 58, 439.

Williams, B. T., Worman, R. K., Jacobs, R. R., and Schenk, W. G., Jr. (1970). An electromagnetic probe for the quantitation of intracardiac flows. Surgery, 67, 1031.

Requests for reprints to Dr. Derek Gibson, Cardiac Department, Brompton Hospital, Fulham Road, London $\mathrm{SW}_{3}$ 6HP. 